\title{
Reconfiguracion del capital en la Argentina. El debate sobre la fraccion hegemonica en el gobierno de Macri*
}

\author{
Daniel Cieza ${ }^{1}$
}

\begin{abstract}
Resumen: El surgimiento de gobiernos reaccionarios en América Latina durante los últimos años estaría indicando un nuevo ciclo conservador que tiene algunas similitudes con los años 90 . Es por eso que algunos autores hablan de un neoliberalismo tardío, con referencia a las gestiones de Mauricio Macri, Michel Temer, Iván Duque o Enrique Peña Nieto. Consideramos que, en rigor, se trata de un fenómeno distinto al neoliberalismo de los 90, ya que en los últimos años se viene operando una reconfiguración del capital y por ende de las clases dominantes. No sólo se ha dado un proceso de financierización, sino que en los últimos años se observa un gran dinamismo de la economía ilícita en el ámbito internacional. En el caso argentino se ha configurado un régimen mafioso. A tres años y medio de Gobierno, se ha consumado una fuga hacia delante de saqueo y autoritarismo. Pero además cobra fuerza la hipótesis de que el "Macrismo" no es un hecho aislado sino expresión de un capitalismo trasnacional mafioso. En efecto, si hay que señalar un sector que se ha beneficiado con la gestión Macrista sería el de grandes corporaciones locales e internacionales que no se caracterizan precisamente por generar inversiones productivas y empleo de calidad, sino que se destacan por ser evasores sistemáticos del cumplimiento de la legislación fiscal y laboral.
\end{abstract}

Resumo: O surgimento de governos reacionários na América Latina nos últimos anos indicaria um novo ciclo conservador que tem algumas semelhanças com a década de 1990. É por isso que alguns autores falam de um neoliberalismo tardio, com referência aos esforços de Mauricio Macri, Michel Temer, Iván Duque ou Enrique Peña Nieto. Acreditamos que, estritamente falando, é um fenômeno diferente do neoliberalismo da década de 1990, pois, nos últimos anos, uma reconfiguração do capital e, portanto, das classes dominantes vem operando. Não apenas ocorreu um processo de financeirização, mas nos últimos anos houve um grande dinamismo da economia ilícita no cenário internacional. No caso da Argentina, um regime mafioso foi criado. Três anos e meio depois do governo, um vazamento à frente de saques e autoritarismo foi consumado. Mas a hipótese de que "Macrismo" não é um evento isolado, mas uma expressão de um capitalismo transnacional mafioso, também está ganhando força. De fato, se for necessário apontar um setor que se beneficiou da administração Macrista, seria o das grandes corporações locais e internacionais que não se caracterizam precisamente por gerar investimentos produtivos e emprego de qualidade, mas que se destacam como evasivas sistemáticas do cumprimento Legislação fiscal e trabalhista.

\section{Introdução}

El surgimiento de gobiernos reaccionarios en América Latina durante los últimos años estaría indicando un nuevo ciclo conservador que tiene algunas similitudes con los años 90. Es por eso que algunos autores hablan de un neoliberalismo tardío, con referencia a las gestiones de Mauricio Macri, Michel Temer, Iván Duque o Enrique Peña Nieto.

Consideramos que, en rigor, se trata de un fenómeno distinto al neoliberalismo de los 90, ya que en los últimos años se viene operando una reconfiguración del capital y por ende de las clases dominantes. No sólo se ha dado un proceso de financierización, sino que en los últimos años se observa un gran dinamismo de la economía ilícita en el ámbito internacional. Este proceso ha sido registrado por algunos economistas como Jorge Beinstein. Dice el economista recientemente fallecido en un artículo póstumo:

Si partimos de los años 1970 es posible describir una suerte de secuencia lógica, que parte de la desviación de fondos originados en la esfera productiva (con rentabilidad 
decreciente) hacia las operaciones financieras tradicionales (compra de títulos públicos, de acciones de las empresas, prestamos de distinto tipo al sector privado, etc.) y desde allí, a medida que éstas últimas se iban saturando, hacia formas de especulación cada vez más veloces y enmarañadas (por ejemplo los "productos financieros derivados”). El fenómeno es conocido como financierización y significa entre otras cosas el alejamiento del interés de las élites económicas respecto de las actividades productivas y su entusiasmo cada vez mayor por la especulación financiera. Aunque como hemos visto ya durante la primera etapa de este proceso, en los años 1980 y 1990, los negocios financieros se fueron conectando cada vez más con actividades ilegales que ofrecían rentabilidades aún mayores. Al mismo tiempo la economía productiva era invadida por tecnologías depredadoras que ofrecían mejorar los beneficios a costa de graves deterioros ambientales y aumentos del desempleo (por ejemplo la minería a cielo abierto, la agricultura basada en transgénicos, la informatización de procesos industriales, etc.).

La euforia financiera estalló en 2008, se estancó la masa de negocios especulativos y en los primeros años de la segunda década del siglo comenzó a desinflarse.

Ya desde antes de dicha ruptura los negocios ilegales ampliaron su importancia y durante el último lustro se produjo una segunda transición desde los negocios financieros legales hacia los ilegales arrastrando a bancos, grupos industriales, comerciales, etc.

Se trata entonces de dos transiciones eslabonadas que desembocan en un sistema global decadente cada vez más saqueador, destructor de culturas, de contextos ambientales, crecientemente parasitario (Beinstein,2019).

En este contexto internacional hay que analizar cual es la fracción hegemónica de las clases dominantes en cada uno de los países. Este permitirá enriquecer el debate sobre el nuevo ciclo abierto en el subcontinente.

\section{El gobierno de Macri}

Hay distintas hipótesis académicas sobre el surgimiento y triunfo de Macri y su partido, el PRO. Algunos sociólogos como Gabriel Vommaro y su equipo lo ven como una novedosa respuesta a la crisis de representación política que emerge en el 2001, liderando una nueva generación que sintoniza con clases medias urbanas y que concentra sus propuestas en la gestión. El PRO sería una heterogénea fuerza, pero sobre todo un "partido del hacer" (Vommaro et al, 2015). Historiadores como Norberto Galasso le ven como "una vuelta al pasado. Mauricio Macri encarna un proyecto neo-liberal, similar al desarrrollado por Carlos Menem en los 90 (Galasso, 2015). Economistas como Eduardo Basualdo y su equipo lo visualizan como expresión de un nuevo bloque de poder donde la fracción hegemónica está conformada por los bancos trasnacionales y empresas extranjeras no industriales (Basualdo et al, 2015). En una dirección novedosa, Jorge Beinstein sostiene que se trata de la progresiva instalación de una dictadura mafiosa. Según el Profesor recientemente fallecido con la llegada de Macri a la presidencia se desencadenó un fenómeno que combina aspectos propios de una restauración conservadora y sus brotes neo-fascistas, con otros que expresan una fuga saqueadora hacia adelante hegemonizada por grupos de la economía subterránea(Beinstein,2017)

En sintonía con esta última postura, exploraremos la hipótesis de que el Macrismo argentino es la expresión local de redes internacionales subterráneas que articulan la economía legal y la economía ilícita. 
La exposición pública de Mauricio Macri como Presidente del Club Boca Juniors, como Alcalde de Buenos Aires y luego como Presidente de la república ha generado centenares de artículos y decenas de libros muy críticos sobre sus accionar. Por ello, solo nos detendremos en plantear interrogantes y reseñar denuncias que involucran a Mauricio Macri y al "Macrismo" en algunos aspectos de su trayectoria reciente, y en particular sobre sus relaciones con redes económicas internacionales.

Mauricio Macri no tiene vocación política en el sentido de "servir al pueblo". No es un apasionado por la acción política, lo que en la jerga partidaria se conoce como un "animal político". Mauricio Macri es un hombre de negocios y un Presidente de la "antipolítica". No tiene brillo profesional, no es un "intelectual” conforme al sentido común. Pero es un "intelectual orgánico" en sentido Gramsciano de un nuevo poder económico que se está configurando en el mundo. A ese poder económico emergente algunos lo llaman economía subterránea organizada en redes trasnacionales. Otros, más directos, lo denominan burguesía trasnacional mafiosa (Forgione, 2016). O para no renunciar a cierta escolástica marxista,se podría usar el concepto de "lumpen-burguesía" que ya utilizaron economistas como Ernest Mandel o Jorge Beinstein (Mandel,1971, Beinstein, 2017).

\section{El presidente del club}

A mediados de los años 90 el grupo Macri “desembarca” en el Club Boca Juniors, ya que Mauricio Macri es elegido Presidente del Club y varios funcionarios del grupo son directivos y asesores. Boca Juniors no es solamente el Club más popular de la Argentina. Está ligado históricamente al Barrio de la Boca, donde predominan los inmigrantes italianos. Y a través de la compra-venta de jugadores y las continuas giras internacionales se vincula con lo que hemos llamado redes internacionales 'hibridas". Francesco Forgione en un artículo titulado "Mafias en torno al deporte más popular del mundo" (Forgione, 2010) muestra las conexiones entre los grandes clubes de fútbol y los grupos mafiosos Hay denuncias sobre ventas irregulares de jugadores, y lavado de dinero. La administración de clubes de fútbol y la venta de jugadores es, sin duda, uno de los capítulos clásicos de las crónicas sobre la mafia.

Hay debates sobre los motivos que llevaron a Mauricio Macri, con importantes directivos del grupo económico familiar, a dedicarse a la gestión de una institución depòrtiva. Hay quienes consideran que el objetivo era la fama y la notoriedad. Otros creen ver un trampolín para la actividad política. También puede sospecharse que el objetivo era obtener ganancias, ya que Mauricio Macri desde sus inicios como dirigente deportivo planteó la necesidad de que los Clubes funcionaran como sociedades anónimas (Galasso, 2015:50). Es difícil de saber los motivos reales y estos no se pueden establecer a partir de sus declaraciones o las de la familia. Lo cierto es que a través de la dirigencia del Club de fútbol más importante de la Argentina, el grupo Macri incrementa sus vínculos internacionales con distintos actores y el futuro Presidente aprende a "pisar el barro".

Hay indicios y denuncias que vinculan al grupo Macri con los carteles colombianos por la compra-venta de Jugadores. Cuando fue Presidente de Boca Juniors Mauricio Macri frecuentó Colombia y mantuvo relaciones con diversos club. Pero lo inexplicable es que priorizó las relaciones con Atletico Nacional de Medellín y el América de Cali. En especial con este último, que 
era controlado por los narcos Rodríguez Orejuela. Boca compró a Deportivo Cali a los jugadores Córdoba, Bermúdez y Vargas. La compra de Córdoba habría sido acordada en una Cárcel con Rodríguez Orejuela. También compra a Serna al Atlético Nacional (Lindner,2017:326). ${ }^{2}$

Los nexos entre narcotráfico y fútbol se extienden a México. Según el prestigioso semanario Proceso de México, el 54\% de los clubes profesionales de este país están en zona narco( Proceso 11/8/17). Entre 1995 y 2008, Boca Juniors jugó 16 partidos amistosos con equipos de México, mas que en los 100 años restantes de las series históricas. La venta de jugadores de fútbol y los partidos "amistosos" son un negocio típico del lavado de dinero.

Algunos jugadores del equipo y el dirigente Roberto Digón, quien fuera Vice-Presidente de Boca Juniors acusaron a Mauricio Macri de maniobras irregulares en la venta de jugadores. Estas acusaciones arreciaron en el año 2005 cuando Marcelo Delgado acusó a Macri de quedarse con un porcentaje de las transferencias de los jugadores, lo que fue apoyado por el ex jugador Jorge Bermúdez y el ex Vicepresidente del Club Roberto Digón (Galasso, 2015:51)

Otro indicio de las relaciones con redes internacionales es el desarrollo de empresas of shore. Mientras fue Presidente de Boca Juniors Mauricio Macri habría desarrollado un gran entramado empresarial en paraísos fiscales. Mauricio Macri y algunos de los funcionarios del grupo que acompañaron a Mauricio en su gestión en Boca Juniors, como Andrés Ibarra, hoy Ministro de Modernización del Gobierno nacional, Néstor Grindetti, Alcalde de Lanús, o Orlando Salvestrini figuran en los informes sobre las empresas montadas en paraísos fiscales que surgen de los "Panamá Papers"3.

Un Club de fútbol importante también es un centro de reclutamiento de cuadros para futuros negocios y operaciones. Por el Club Boca Juniors bajo la Presidencia de Macri circulan figuras como el actual Fiscal Federal Carlos Stornelli, el Jefe de la Agencia Federal de Inteligencia, Gustavo Arribas, el ex funcionario judicial Guillermo Montenegro, actualmente Embajador en Uruguay, el actual Presidente del Club y operador judicial del Macrismo, Daniel Angelici, los actuales funcionarios judiciales Lijo, Polliscita, Plee y el ex jefe de la Policía Metropolitana Jorge (Fino) Palacios.

Finalmente en los años 90 se funda la empresa aérea Mac Air ligada al club Boca Juniors. La empresa surge en 1996, como propiedad del Grupo Macri y dispone de modernos Jets. En la década siguiente desarrolla rutas en el norte del país en alianza con Aerochaco. Hay denuncias que esos vuelos podrían ser usados por narco-traficante. Resulta incomprensible desde la lógica empresarial la incursión del grupo Macri en la aviación comercial. Según periodistas de la región, como Fabían Ferrante, la empresa aérea fue acusada de negocios con narcotraficantes y con el Club Boca Juniors ${ }^{4}$.

\section{El jefe de gobierno}

A comienzos del nuevo milenio Mauricio Macri exterioriza su decisión de disputar cargos políticos. Su herramienta es una nueva fuerza política llamada Propuesta Republicana (PRO). En 2003 disputa la jefatura de Gobierno de Buenos Aires pero es derrotado. En 2005 es electo diputado nacional por el distrito capitalino. 
En el año 2007 Mauricio Macri gana las elecciones como Jefe de Gobierno de Buenos Aires Lo acompañan en la gestión ex funcionarios de su grupo empresario como Nestor Grindetti , Daniel Chaín o Andrés Ibarra e incorpora a diversos miembros de la Fundación Creer y Crecer y del Grupo Sophía como Horacio Rodriguez Larreta, María Eugenia Vidal, o Carolina Stanley, a sus equipos de gobierno.

Con Mauricio Macri como Alcalde de la capital argentina, el grupo familiar sigue activo en sus negocios y sus relaciones políticas. Compra tierras en las provincias de Salta, y Santiago del Estero. En especial se destaca el gran establecimiento conocido como el "Yuto SA" que consta de 20.000 hectáreas en Salta (Galasso, 2015:79)

El grupo económico Macri cultiva relaciones políticas con dirigentes justicialistas de provincias de frontera, como Juan Carlos Romero (Salta) y Ramon Puerta (Misiones) y adquiere importantes establecimientos rurales en ambas provincias. Mauricio Macri nombra en el Gobierno de Buenos Aires a importantes ex funcionarios de Ramón Puerta y Juan Carlos Romero (Schiavoni, Durand Cornejo, Javier David)

Además el grupo forma varias empresas en el exterior. Según los informes sobre los "Panama Papers" y denuncias judiciales hay unas 50 empresas vinculadas a la familia (MaradeoDamiani,2018:366).

A fines de la primera década del siglo XX, con Mauricio Macri como Alcalde de Buenos Aires, el grupo continúa en la obra pública a través de IECSA dirigida por un primo (Calcaterra) y de las relaciones con Nicolás Caputo. Este empresario es el "amigo del alma" de Mauricio Macri y dirige una empresa de origen familiar dedicada a la construcción. Durante el mandato de Macri como Alcalde porteño IECSA habría pagado una importante coima, para ganar la licitación, junto a Odebretch, del soterramiento del ferrocarril Sarmiento. ${ }^{6}$

Por otro lado crea otra Fundación, llamada Pensar, donde trabajan entre otros los jóvenes empresarios Francisco Cabrera, Miguel Braun, Rogelio Frigerio y Guillermo Dietrich, que luego serían importantes funcionarios. El co-fundador de esta Fundación, y ex Presidente de la misma, Matteo Goretti, de origen italiano, fue procesado en 2012, cuando ejercía como Vocal de la Fundación, por complicidad en el tráfico internacional de piezas arqueológicas. Goretti también fue procesado junto a Hernán Lombardi por lavado de dinero a través de la Fundación.

Llama la atención los continuos viajes al exterior durante su gestión en la Ciudad de Buenos Aires. Gabriela Cerruti denunció la inusitada cantidad de viajes oficiales. El historiador Galasso, al analizar ese período titula "Un jefe de Gobierno muy viajero"(Galasso, 2015). En esta etapa traba relaciones con mega-empresarios como Joe Lewis o Florentino Perez. ${ }^{7}$

El Alcalde mostró cierta preocupación por la seguridad pública, pero sobre todo por el espionaje de asuntos privados. El jefe de la Policía Metropolitana, Jorge "Fino Palacios, ex jefe de Seguridad de Boca Juniors, fue procesado por escuchas ilegales sobre una pariente de Macri y en la causa también fue procesado el Jefe de Gobierno (Cerruti, 2010:335-38).

Como contrapartida, el Alcalde de la Capital argentina no se muestra muy activo ante algunos estragos que sacuden la ciudad. Entre ellos el incendio de un depósito de la empresa Iron Mountain en febrero de 2014 donde nueve personas murieron, entre bomberos y rescatistas, mientras que otras siete resultaron gravemente heridas; y dos incendios de talleres textiles clandestinos en 2015, donde murieron dos niños. Esta presunta inacción origina duras críticas de familiares de las 
víctimas y de movimiento sociales, y dudas sobre los documentos sensibles de algunas empresas que desaparecieron en el incendio.

\section{Alianzas y venganzas de un presidente calabres}

Durante el 2015 la fuerza de Mauricio Macri, el PRO, realiza una alianza electoral con la Unión Cívica Radical (UCR) y la Coalición Cívica (C.C.) y bajo el nombre de CAMBIEMOS disputa la Presidencia de la Nación. Gana por estrecho margen al candidato del Frente para la Victoria, Daniel Scioli.

Mauricio Macri ejerce la Presidencia de la Nación argentina a partir del 10 de diciembre de 2015. Los periodistas de investigación que son opositores políticos lo suelen llamar "Gato"8 mientras que algunos periodistas que escriben en medios afines al Gobierno, se refieren a él como "el calabrés". La sombra de la mafia siempre está presente.

En 2015 es electo Presidente de la Nación y nombra como principales funcionarios a diversos Ceos de grandes empresas y a los jóvenes de la Fundación Pensar. Un análisis del personal político superior del Estado muestra entre los rangos de Ministro, Secretario y Subsecretario a un importante número de funcionarios que provienen de grandes empresas y bancos internacionales (Basualdo, 2017, Cieza, 2016). Por ejemplo los Ministros de Energía Juan Aranguren, de Relaciones Exteriores, y Susana Malcorra, fueron CEOs de Shell y de IBM, y el Secretario de la Jefatura de Gabinete, Gustavo Lopetegui fue Ceo de LAN. A su vez, el Ministro de Hacienda, Alfonso Prat Gay fue funcionario de la Banca Morgan y Luis Caputo, Secretario de Finanzas del Deutsch Bank.

El primer gabinete de Mauricio Macri no sólo refleja acuerdos electorales. También revela alianzas sociales con grupos de la "oligarquía". El estratégico cargo de Jefe de Gabinete y la Secretaría de Comercio son ocupados por Marcos Peña Braun y Miguel Braun. Los Braun constituyen un grupo familiar centenario originado en Punta Arenas, Chile, que en alianza con la familia Menendez Bethy construyen el mayor imperio económico de la Patagonia argentina9. El Grupo Braun, "tiene funcionarios en la Jefatura del Gabinete, la Secretaría de la presidencia de la Nación y en los ministerios de Producción, Educación, Cultura, Modernización, Agroindustria, Energía y Relaciones Exteriores. También forman parte de la Anses y del Gobierno de la Ciudad de Buenos Aires", según una investigación realizada por Guillermo Delgado Jordán (Delgado Jordán 2017, Cibeyra, 2017)

Pero además de este grupo de parientes con cargos en el Estado, el grupo Braun a través de sus principales empresas, como el Banco Galicia y La Anónima, ha contribuído con importantes funcionarios del Gobierno de Macri. Se destaca Nicolás Dujovne, actual Ministro de Economía, quien se desempeñara como Economista Jefe del Banco de los Braun por más de diez años.

Otra familia "oligárquica" con alianzas con Macri es la familia Bulrich, que aportó dos Ministros al primer gabinete de Mauricio Macri. Esteban Bulrich, el primer Ministro de Educación de Macri y actualmente Senador pertenece a una familia tradicional vinculada al agro bonaerense. En su actividad privada fue directivo de una empresa citrícola de Tucumán y luego se dedicó a la política. Pero además nombra como Ministra de Seguridad a Patricia Bulrich, dirigente política de sinuosa trayectoria y con inocultables vínculos con Agencias de Estados Unidos e Israel ${ }^{10 .}$ 
Al ser electo Presidente, Mauricio Macri dice haber dejado los negocios de la familia pero sin embargo sigue realizando acciones dudosas: otorga nuevas rutas aéreas a una empresa colombiana que sucede al grupo Mac Air; intenta condonar deudas de su grupo familiar en el affaire del Correo; por un decreto de necesidad y urgencia permite "blanquear" dinero del exterior a sus parientes directos; permite que el ex Ceo y accionista de Farmacity, Gustavo Quintana maneje la política de medicamentos; nombra como Jefe de Inteligencia a Gustavo Arribas, acusado de vender jugadores de Boca Juniors en forma irregular y de recibir coimas en Brasil de Grupo Odebretch.

Hay funcionarios que no continuaron en el cargo y que habrían sido despedidos por orden del Presidente por cuestionar algunas de estas decisiones. Entre ellos el Ministro de Hacienda Pratt Gay, la titular de Aerolíneas Argentinas Isela Constantini, el Presidente del Banco Nación, Carlos Melconían, y el titular del PAMI, Carlos Regazzon. El apodo de "el calabrés" hace referencia a un personaje vengativo y que no perdona la interferencia en "negocios". Según el periodista Franco Lindner:

“...Nadie está en condiciones de afirmar que el presidente argentino integre las filas de la Ndrangheta, pero sin dudas la sangre tira. Un calabrés no olvida ni perdona. Es implacable con sus rivales. Sobre todo con los que pretenden entrometerse en sus negocios. Contra estos últimos la venganza será terrible.."

Y agrega que las cuatro "renuncias" tienen algo en común "todos los despedidos se habían animado, desde sus cargos, a cuestionar los negocios apadrinados por el capo"(Lindner, 2017:153).

Finalmente, el acuerdo con el Fondo Monetario Internacional (FMI) alcanzado en el 2018, con el apoyo explícito del Presidente Donald Trump, revela otras alianzas. En ocasión del mayor préstamo que el FMI ha otorgado en los últimos años, Trump recordó que "hizo negocios" con la familia Macri en otras épocas. Las consecuencias de este nuevo negocio público, realizado sin aprobación del Congreso, seguramente lo pagarán las nuevas generaciones de argentinos. El préstamo del FMI no sólo significa una forma de sujeción a nuestro país, sino que implica una virtual hipoteca al presupuesto nacional que demorará varios años en levantarse. ${ }^{11}$

\section{Promesas y resultados}

Es muy difícil establecer el proyecto de la coalición que dirige Macri, dado que se trata de una alianza heterogénea con un nombre que evoca a un cambio de carácter progresista y a una serie de propuestas. Pero también sabemos que los Gobiernos suelen hacer lo contrario a sus promesas de campaña y que, por lo tanto, deben ser evaluados por sus resultados. Por el momento conocemos los resultados de las políticas del Gobierno de Cambiemos a tres años del inicio de su gestión: inflación anual superior al 46\% en 2018, aumento de la pobreza y la indigencia, baja importante de los salarios y de haberes previsionales, incremento sideral de la deuda externa, caída del producto industrial, aumento del desempleo y de la precarización laboral, deterioro notable del sistema de salud pública, retroceso en la educación pública, vulneración sistemática del estado de derecho, nulos resultados en el combate al narcotráfico, y total impunidad para los parientes y amigos del Presidente. 
Mención especial merecen sus principales promesas de campaña: pobreza 0 y acabar con el narcotráfico. La pobreza medida oficialmente llegó al 27\% a fines de 2017 y supera el 30\% según todas las estimaciones del año 2018. Respecto al narcotráfico, la Argentina sigue siendo uno de los principales puertos de embarque de la cocaína que se dirige hacia el hemisferio norte. En los tres últimos años se detectaron en Calabria y en Canadá diversos cargamentos de cocaína provenientes de la Argentina. Todos estos casos no fueron resueltos por las fuerzas de seguridad argentinas y sirven para ilustrar que el problema continúa. Y lo más llamativo es que los únicos beneficiarios son justamente los mafiosos calabreses, paisanos del Sr. Presidente.

No hay muchos indicios de que el Gobierno de Macri esté tomando con seriedad su promesa de que entre las tres prioridades de la gestión estaba la lucha contra el narco-tráfico. Expertos en el tema, como Juan Tokatlian consideran que ni siquiera se ha realizado un diagnóstico aceptable sobre la problemática de las drogas (Tokatlian, 2017)

En el informe de la Oficina de las Naciones Unidas contra la Droga y el Delito, de 2013, Argentina aparece en el tercer puesto del ranking mundial de países mencionados con mayor frecuencia como lugar de emisión en relación a distintos casos de incautación de drogas Autoridades italianas habían advertido sobre la presencia de la mafia calabresa en el país

Sin embargo, y a pesar de que en Agosto de 2015 y a principios de 2017 se detectan nuevamente cargamentos de cocaína provenientes de Argentina en el Puerto calabrés de Gioia Tauro, no se conocen detenidos ni investigaciones judiciales al respecto. Evidentemente falta una labor de inteligencia criminal ¿Serán funcionarios como Gustavo Arribas los más capacitados para encabezar el combate a la mafia?

\section{El debate sobre las mafias}

Cuando se habla de mafia en la Argentina macrista se apunta a los abogados laboralistas, a los sindicalistas o a los vendedores informales del conurbano bonaerense, o sea una típica maniobra de distracción. Mauricio Macri nunca ha mencionado la mafia calabresa, la más importante del mundo. ${ }^{12}$ El politólogo y asesor en marketing electoral del Presidente Macri, Jaime Durán Barba, utiliza la palabra mafia con un sentido cercano al sentido común. No porque ignore el debate académico, sino porque su oficio es dirigir campañas política. Según el politólogo ecuatoriano el vocablo es aplicable a trabajadores informales que se dedican al narcomenudeo y a la venta de productos falsificados, o a los que obtienen beneficios indebidos de programas oficiales.

Lo curioso del uso de este concepto es que reduce el concepto de mafia a grupos marginales y soslaya el problema de los delitos de los poderosos. Por ejemplo no se habla de mafia respecto al lavado de dinero o los delitos financieros. O se considera mafiosos a trabajadores que viven en la informalidad, cuando el debate académico ha identificado como una variante del crimen organizado al "caporalato" que consiste en explotar laboralmente a trabajadores informales y migrantes.

¿Hay un error conceptual sobre las mafias realmente existentes? No lo creemos. Mauricio Macri no es un político de laboratorio sino un hombre de negocios y de acción. Reconoce su identidad calabresa. Fue socio de la mayor empresa de residuos sólidos sospechada de vinculaciones con la mafia. Tuvo contactos con jefes narcos colombianos por la compra-venta de jugadores de Boca 
Juniors. Sabe lo que son los paraísos fiscales, donde conviven hombres de negocios y representantes de las mafias. Defendió públicamente a "Chicho "Serna, procesado por lavado de activos junto a la viuda de Pablo Escobar y su hijo. ${ }^{13}$

En suma: Se ataca a mafias inexistentes o poco significativas, cuando las mafias más importantes del mundo muy probablemente tengan relaciones con varios funcionarios del Gobierno. Se ha dicho hasta el cansancio que la mafia calabresa se destaca por infiltrar estructuras gubernamentales y no parece que la Argentina sea la excepción. Asimismo, los cárteles colombianos realizan un lavado de activos sistemático.

Pero hay algo más que aclarar al respecto. Según los datos recopilados por periodistas de investigación podría haber negocios y decisiones recientes que deberían ser analizados en el marco de una política pública antimafia.

Debería haber mayor control sobre zonas del norte del país escasamente "radarizadas" donde se han hecho grandes negocios con la adquisición de tierras ${ }^{14}$. Hay denuncias por adquisiciones irregulares y desmontes de tierras que afectarían derechos de incidencia colectiva. Pero algunos periodistas de investigación sospechan que el objetivo de estas adquisiciones no radica en el rendimiento de la soja, sino en el control de zonas que tienen mucho valor porque las utiliza el narcotráfico internacional. Es conocido que existe un corredor de la cocaína a partir de los cargamentos provenientes de Bolivia que aterrizan en establecimientos rurales de Salta y Santiago del Estero. El periodista Mauro Federico, en su libro "El país narco" documenta correctamente esta cuestión (Federico, 2011)

Por otra parte continúan apareciendo empresas off-shore con participación accionaria del clan Macri y sus colaboradores. Se ha denunciado que los miembros de la familia Macri participan en 50 empresas. También aparecen involucrados varios funcionarios y ex funcionarios como Luis Caputo, Juan José Aranguren, Claudio Avruj, Leandro Cuccioli y Eduardo Martelli. Como se sabe, el mero hecho de poseer una empresa of- shore no es un delito, pero en la mayoría de los casos se trata de algún delito económico-financiero.

Asimismo se han tomado medidas que podrían significar un menor control sobre otra actividad de las mafias. Se trata de los controles sobre el trabajo forzoso que estaba implementando el RENATEA, un organismo público creado por el Kirchnerismo para fiscalizar la precarización laboral en el agro. Aprovechando un fallo judicial, el Macrismo elimina este organismo de control y vuelve a instalar el RENATRE, un organismo controlado por la Sociedad Rural y el gremio de los peones rurales que dirigía Jerónimo "Momo" Venegas. Como consecuencia disminuyen drásticamente las denuncias judiciales sobre trabajo forzoso. (Premici, 2016) También disminuyen los controles sobre el trabajo forzoso en las grandes ciudades. Grandes firmas de indumentaria suelen subcontratar trabajo forzoso en el área metropolitana. Hubo incendios en talleres textiles clandestinos en la ciudad de Buenos Aires en 2006 y $2015 .{ }^{15}$ Entre las empresas denunciadas por trabajo forzoso se menciona la firma Awada, propiedad de la familia de la esposa de Mauricio Macri. En la gestión porteña de Macri, como en la gestión presidencial se han reducido las inspecciones de los organismos del trabajo. ${ }^{16}$

Finalmente siguen apareciendo empresas de aviación regionales con escasos controles estatales. El caso más notorio es el de Avianca en la Argentina, gerenciada por Carlos Colunga que antes 
dirigía MacAir, la empresa aérea del grupo Macri. Otro caso es Flybondi, que estaría controlada por el reciente ex miembro del gabinete, Mario Quintana. Dirigentes sindicales aeronáuticos vienen denunciando irregularidades en la habilitación de estas empresas

En síntesis, mientras se ataca a mafias de dudosa existencia, el Presidente Macri y su entorno omiten políticas de prevención sobre las mafias realmente existentes

\section{La "Famiglia"}

Cuando los antropólogos analizan la familia prefieren hablar de un grupo más amplia llamado familia extensa. Si tomamos el grupo familiar encabezado por Mauricio Macri vamos a encontrar hermanos, primos, "amigos del alma”, cuñados y amigos íntimos muy interesantes.

Dicen que Franco Macri siempre se opuso a la participación de su primogénito en política ya que muchos empresarios prefieren ser "invisibles". Sin embargo, los Macri hoy son notorios. La última generación de la familia está en primer plano ocupando puestos en las empresas y en el Gobierno. El más famoso es Mauricio, apodado "El Calabrés” en el mundo empresario, cuyo perfil ya hemos tratado. Pero también se están conociendo datos de sus hermanos, primos y amigos. La cercanía al poder les otorga cierta impunidad coyuntural, pero los expone a numerosas investigaciones de periodistas.

Gianfranco Macri, hijo de Franco y hermano de Mauricio, es un empresario poseedor de propiedades rurales en Salta y empresas off-shore. Fue acusado de lavado de dinero y regularizó su situación ante el fisco tras ser denunciado por la Procuraduría de Criminalidad Económica y Lavado de Activos (Procelac), en 2016. Investigación llevada a cabo en base a la información enviada por la fiscalía federal de Hamburgo sobre movimientos sospechosos en una cuenta de la sociedad en el Banco UBS, en Alemania. Además blanqueó 35 millones de dólares en el exterior aprovechando un decreto firmado por su hermano. Recientemente ha sido denunciado por ser favorecido en negocios de energía eólica.

Jorge Macri, hijo de Antonio y primo de Mauricio Macri, es Intendente de Vicente López. Ha sido procesado en dos causas por lavado de dinero a través de compras de inmuebles con una empresa of-shore y por un contrato de la Municipalidad de Vicente López con una empresa de narcos colombianos. También es mencionado en la causa del financiamiento ilícito de Cambiemos en 2015 y 2017. Incluso, Elisa Carrió lo ha descalificado como candidato de Cabiemos acusándolo de vínculos con el narcotráfico ${ }^{17}$.

El otro primo es Angelo Calcaterra, hijo de María Pía y Antonio Calcaterra, acusado por lavado de dinero en el caso Odebretch y que también es uno de los "arrepentidos" en el caso de los "Cuadernos".

El tercer "primo" es el menos conocido y se llama Eduardo "Lalo" Macri. Fue Ministro de Economía en Entre Ríos durante los '90 y estuvo acusado de enriquecimiento ilícito. En 2018 fue denunciado por la compra de un campo en forma fraudulenta en Salta. Su parentesco no está demostrado aunque diarios del interior, como el Tribuno de Salta, o la prensa de Entre Ríos lo dan por seguro.

El "amigo del alma" de Mauricio Macri es Nicolás Caputo, compañero de estudios en el Colegio Cardenal Newman. Fue dueño de una empresa constructora familiar (Caputo S.A.), socio de Macri en la empresa Mirgor y con inversiones en el sector energético a través de SEDESA, 
Central Puerto y Pampa Energía. Adquirió propiedades rurales en la provincia de Salta en sociedad con los Macri. Fue uno de los principales contratistas durante la Jefatura de Gobierno de la Ciudad de Buenos Aires de Mauricio Macri, a través de la empresa SES (Rafele, 2017). Su primo, Luis Caputo, fue Secretario y Ministro de Finanzas del Gobierno de Macri y luego fue Presidente del Banco Central. Luis tiene una larga trayectoria en el mundo de las finanzas, desempeñándose como funcionario de J.P. Morgan y el Deutsche Bank, además de ser directivo de una Consultora propia.

Esta nueva generación de descendientes de italianos está conformada por profesionales, arquitectos, ingenieros, economistas y contadores con posgrados en el exterior. Llama la atención que casi todos están investigados o procesados algún tipo de fraude o por lavado de dinero. De alguna forma pareciera que siguen vinculados a una tradición que tiene como regla cardinal buscar atajos ante las leyes vigentes.

El cuñado más notorio de Mauricio Macri es Daniel Awada, hermano de su tercera esposa. Se trata de un importante empresario de la industria de la confección y titular de la firma Cheeky. Ha sido denunciado por importaciones irregulares de prendas de vestir y por sub-contratar trabajo forzoso $^{18}$

Hay otros "amigos íntimos" de Mauricio Macri. Se destacan Marcelo Mindlin y John Lewis. El primero es el presunto comprador de IECSA la empresa de obras públicas de la familia, que se benefició con la ley de "blanqueo de capitales" y con el aumento de las tarifas eléctricas (por ser dueño de EDENOR). El segundo es un importante accionista de las mayores empresas eléctricas. Pareciera además que Mindlin es representante o testaferro de Lewis, titular de la empresa internacional Tavistock Group. En la Argentina adquiere la estancia "Lago Escondido" y controla Pampa Energía, entre otros negocios. Ha sido denunciado por grupos ecologistas por apropiarse de accesos públicos al lago.

\section{Un recorrido "accidentado" pero exitoso}

Posiblemente como consecuencia de su exposición pública han surgido numerosas acusaciones y denuncias sobre la actuación de Mauricio Macri como empresario y como dirigente político. Solo algunas acusaciones fueron judicializadas pero igualmente acumula un verdadero record de denuncias judiciales. Según periodistas de investigación al llegar a Presidente había sido objeto de 240 denuncias judiciales y como Presidente fue objeto de 92 denuncias más.

Del cúmulo de acusaciones surgen antecedentes, algunos precisos y concordantes, que han sido recopilados por periodistas de investigación y que configuran un recorrido muy controvertido que podría relacionarse con la hipótesis de nuestra investigación. Ya hemos hecho referencia a la mayoría de ellos en este artículo pero a modo de conclusión intentamos una síntesis panorámica de su "prontuario", que incluye a colaboradores estrechos y familiares.

a) Fue procesado por contrabando de autos a Uruguay cuando dirigía SEVEL- FIAT. Se lo absolvió por "falta de mérito" en un tribunal en lo penal económico. En 2001, días después que Macri anuncia su decisión de intervenir en política es nuevamente procesado por el Juez Liporace, pero finalmente es desprocesado por "cosa juzgada" La Corte Suprema mantuvo el desprocesamiento. Más tarde, algunos de sus miembros fueron destituídos por el "caso Macri”, entre otros cargos (La 
Nación, 21 de mayo de 2010). También fue procesado en 2010, cuando era Jefe de Gobierno de Buenos Aires, por “escuchas ilegales”(Cerruti, 2010). En 2018 el Tribunal de Casación consideró nulas las actuaciones.

b) Fué acusado públicamente de negociar en forma irregular la venta de jugadores de fútbol , en ocasión de su paso por la presidencia del club Boca Juniors . Está sospechado de cobrar "coimas" por la venta de jugadores (Galasso, 2015:51).

c) Fué fotografiado en ambientes prostibularios de Cancún en un club del ex agente de la SIDE Raúl Martins, sospechado de trata de personas y de vínculos con los Zetas, un grupo del crimen organizado. Martins habría financiado la campaña del PRO según denuncias judiciales (Maradeo-Damiani,2018:133-8, Lindner, 2017:313)

d) Frecuentaba una mansión de la familia Nocella en Cerdeña, donde se reunían personajes del "jet set" italiano. Esta familia estaba asociada a los Macri, como se prueba en la investigación de la empresa Owners, que aparece en los "Panamá Papers". Esto motiva una denuncia penal del diputado Darío Martínez (Maradeo-Damiani, 2018:365).Se dice que Nocella estaba vinculado a la Logia P 2 (Steinleger, 2016)

e) Ha sido denunciado por periodistas por la participación en empresas radicadas en "guaridas" fiscales del exterior. Algunas denuncias fueron judicializadas y fue imputado al menos en una causa (Maradeo-Damiani, 2018:361-6)

f) Es mencionado por tener relaciones con empresas investigadas por la trata de personas con fines laborales, junto a su actual esposa. Hay denuncias realizadas por la Fundación Alameda contra las empresas Cheeky y Awada (Lieutier, 2010:176)

g) Fue denunciado por intervenir en la autorización de líneas aéreas regionales (MaradeoDamiani, 2018, 329-31)

h) Está sospechado de intentar condonar ilícitamente una deuda de la empresa familiar Correo Argentino con el Estado nacional (Maradeo-Damiani, 2018:309-27)

i) Permitió que sus familiares directos participaran en un "blanqueo" de capitales fugados a través de un decreto, lo cual motivó varias denuncias (Maradeo-Damiani, 2018:359; Cerruti, 2018:52)

f) La coalición política que encabeza está sospechada de un financiamiento ilícito en las elecciones de 2015 y 2017. Se destaca una investigación periodística realizada por Juan Amorín para el Programa "El Destape" (Rafele-Grigera,2017:220-31, Amorín,2018)

g) Algunas de las empresas que dirigió, como IECSA, se encuentran acusadas de pagar sobornos para obtener sobreprecios en la obra pública (Cerruti, 2018)

h) Ha sido denunciado por favorecer empresas que estuvieron vinculadas a su grupo y que actualmente manejan sus aliados o socios como Nicolás Caputo, Marcelo Mindlin, Carlos Miguens Bemberg, Florentino Perez etc. Se trata de empresas como IECSA, Pampa Energía, Abertis o Citrícola San Miguel. Estas empresas siguen obteniendo ganancias importantes y se habrían favorecido con diversas medidas del Gobierno,como el aumento de las tarifas eléctricas y de los peajes en el área metropolitana, o el loby a favor de la exportación de limones. Se sospecha que la familia presidencial aún sigue teniendo fuertes intereses en estos negocios (Rafele-Grigera, 2017; Cerruti, 2018) 
i) Según una denuncia del Defensor del Pueblo bonaerense contra el Estado nacional, se habilitó a las empresas Edenor y Edesur para que avancen con una suba "ilegal, irrazonable e inconstitucional" de la tarifa eléctrica, que trepó casi 1.500 por ciento en el lapso de dos años.Asimismo se condonó deudas a dichas empresa,dónde serían accionistas amigos del Presidente como Joe Lewis y Nicolás Caputo(Cerruti, 2018:135-136)

j) Durante su Gobierno se anularon normas de control sobre las empresas of-shore. Según un artículo de Tomás Lukin titulado "Argentina es of shore friendly" (P 12,18/10/2018) la Inspección General de Justicia redujo los requisitos para la inscripción de empresas extranjeras en Argentina.

k) Directivos de la Fundación Pensar, que él fundó y dirigió, como Hernán Lombardi y Mateo Goretti fueron procesados por lavado de activos y complicidad en robos de obras de arte (en el caso de Goretti).

1) Según denuncias de algunos abogados, en su Gobierno se habría formado una red de espías y fiscales que realizan espionaje ilegal y extorsiones. Fueron detenidos Marcelo D Alessio y 3 ex agentes de la Agencia Federal de Inteligencia (AFI), y denunciados Fiscales como Carlos Stornelli, Juan Bidone y Sebastian Scalera.

La simple lectura de los datos precedentes sugiere que en su práctica concreta Mauricio Macri ha sido un hombre de negocios que se ha manejado con sus propias reglas que no siempre coinciden con las normas jurídicas y éticas vigentes. Su carrera hacia el ejercicio de la primera magistratura y su gestión presidencial no ha sido un "sacrificio" en aras de un ideal altruísta como ha sugerido su madre, sino un raid "exitoso" que le ha permitido mejorar sus negocios y los de su entorno, como sugirió su padre. En la gestión de Mauricio Macri no hubo fracasos sino designios inconfesables coronados por el éxito.

\section{Conclusiones y perspectivas}

Desde un punto de vista general, las políticas públicas implementadas por Mauricio Macri coinciden con las "recomendaciones" del Gobierno de Estados Unidos y favorecen a un pequeño grupo de sectores del gran capital concentrado, como son algunos Bancos y fondos de inversión, el complejo energético, empresas constructoras y capitales especulativos. Con el corset impuesto por el acuerdo con el Fondo Monetario Internacional y tasas de referencia de alrededor del $70 \%$, no hay ninguna posibilidad de políticas productivas o de mejorar la distribución de la riqueza.

A tres años y medio de Gobierno, se confirma la predicción de Jorge Beinstein: se ha consumado una fuga hacia delante de saqueo y autoritarismo. Pero además cobra fuerza la hipótesis de que el "Macrismo" no es un hecho aislado sino expresión de un capitalismo trasnacional mafioso.

En efecto, si hay que señalar un sector que se ha beneficiado con la gestión Macrista sería el de grandes corporaciones locales e internacionales que no se caracterizan precisamente por generar inversiones productivas y empleo de calidad, sino que se destacan por ser evasores sistemáticos del cumplimiento de la legislación fiscal y laboral. Se trata de grupos económicos con decenas de empresas radicadas en guaridas fiscales, que no cuentan con una planta permanente y protegida de trabajadores proporcional a su poderío económico, y subcontratan trabajo precario y/o forzoso, y que se especializan en obtener ganancias extraordinarias en operaciones con fondos de origen dudoso. Este sector es hoy muy dinámico en la economía internacional y forma parte de la llama- 
da economía subterránea o sumergida. Se puede debatir como caracterizar o definir este sector. ¿Burguesía trasnacional mafiosa? ¿Lumpen-burguesía parasitaria y depredadora? Pero hay una cuestión indudable e irrefutable. Este sector viola en forma cotidiana y sistemática el derecho internacional de los derechos humanos que fue edificado pacientemente en la segunda mitad del siglo $\mathrm{XX}$ como intento de frenar la repetición de la barbarie.

La discusión sobre la fracción hegemónica en el Gobierno de Macri no es ociosa. Si se trata de la hegemonía de una fracción de la economía subterránea, apoyada por Estados Unidos, como creemos, las perspectivas de continuidad son efímeras. En este sentido se abren grandes posibilidades para que en las elecciones de este año el Macrismo sea desplazado del Gobierno por sectores más vinculados al mercado interno que enarbolen un proyecto de "capitalismo nacional".

\section{Notes}

1 Profesor e investigador de la Facultad de Ciencias Sociales de la Universidad de Buenos Aires. E-mail: danielcieza22@gmail.com.

2 Existe evidencia de que después del desmantelamiento del Cartel de Cali a finales de los años noventa, el América de Cali continuó recibiendo dinero de redes de tráfico de drogas. El Departamento del Tesoro de Estados Unidos incluyó el equipo en su lista de "capos"(Kingpin list) en 1999 debido a sus continuos vínculos con los hermanos Rodríguez Orejuela, congelando todos los activos del equipo en Estados Unidos.

3 El intermediario en armar un entramado off shore de empresas fue Pablo Clusellas, luego funcionario de Macri. Según Hugo Alconada Mon,Clusellas fue el contacto entre el Estudio panameño Mossack Fonseca y los Macri. Entre otras empresas se destaca Fleg, que se suma a Grandberry Inc, y Lorela SA en las que aparece Salvestrini.

4 La ruta del dinero K, la ruta de la droga, y la campaña de "Cambiemos" se titula la nota de Fabbián Ferrante publicada el 07/06/2016 en Tribuna de Periodistas.

5 Esto surge de la confesión de Vazquez, asesor de Ricardo Jaime,en una causa judicial.

6 Matteo Goretti es un politólogo que colecciona piezas arqueológicas.Fue beneficiado por la prescripción en la causa sobre complicidad en robo de obras de arte.

7 Joe Lewis es un magnate inglés, considerado dentro de los diez millonarios más importantes de Reino Unido, que vive en un yate en las islas Bahamas y es dueño del Club de futbol británico Tottenham.Es propietario del grupo Tavistock. Florentino Perez controla ACS, un grupo de empresas de construcción de infraestructuras y energía, y de servicios,líder mundial en el negocio de los Peajes.Es el Presidente del Real Madrid de España y ha compartido alianzas transitorias de empresas con el grupo Macri.

8 En el argot de algunas regiones, "Gato" significa gatillero, delincuente o una persona despreciable. En un Tango de la década del 30 Homero Manzi lo define como un sujeto:

“...Que se muestra cuando hay buenas, pero en las malas se esfuma, que se estira en la aliviada y se encoge en el cinchar, que se apropia de lo ajeno, que se viste con espuma, que aparenta estar sobrado y no tiene pa empezar..."

9 Una genealogía actualizada del Grupo Braun-Menendez puede verse en un artículo de Jose Luis Torres, publicado en Trabajo y Derechos Humanos Nro 2, UBA, 2016, y en el libro de Alonso "Menendez , Rey de la Patagonia(2014).

10 Para mayor información sobre los Bulrich del Gabinete de Macri puede verse la revista Trabajo y Derechos Humanos Nro 3,UBA, 2017.

11 Con el endeudamiento del Macrismo y el préstamo delFMI la deuda externa Argentina ascienda a 300.000 millones de dólares a fines del 2018 ( el 100\% del PBI) y es imposible de pagar en los plazos pactados. 
12 En Marzo de 2019 se realizó un Seminario Anti-Mafia organizado por algunos legisladores argentinos y diplomáticos italianos,que fue inaugurado por Mauricio Macri,pero el primer mandatario no mencionó a la 'ndrangheta.

13 Pocos días después que Serna fuera procesado, Macri lo defendió en ocasión de la ceremonia de asunción del Presidente Iván Duke en Colombia, y luergo lo invitó a jugar fútbol a la residencia de Olivos.

14 Grupos ecologistas han denunciado a Gianfranco Macri, y a personas del entorno del Presidente como Nicolás y Luis Caputo, Pablo Clusellas, José Torello o Alejandro Braun Peña, además del presunto primo del Presidente, Eduardo "Lalo" Macri por acaparar inmuebles rurales en el chaco salteño y producir desmontes.

15 La Fundación Alameda, ya había denunciado la muerte de 6 personas en un Taller textil clandestino de la Ciudad de Buenos Aires en el año 2006 y vuelve a presentar una denuncia ante otro incendio y muerte de dos personas en 2015.

16 En Buenos Aires en 2009 se aprobó la Ley 3.019 que obliga a la Ciudad a inspeccionar y regularizar los talleres textiles. Macri la promulgó, pero la ley nunca fue reglamentada". A nivel naciona la gestión de Macri redujo la estructura del Ministerio de Trabajo, que pasa a ser una Secretaría.

17 Diario Perfil,24 de Mayo 2017, CABA.

18 Una investigación del diario Perfil revela que funcionarios de la Aduana encontraron dos contenedores que ingresaron al país a nombre de una firma apócrifa utilizada por la mafia de los contenedores para el contrabando de textiles, conteniendo ropa de las marcas Cheeky y Como Quieres que te Quiera, de Daniel Awada. Por otra parte la empresa Cheeky ha sido denunciada en tres oportunidades por la Fundación Alameda por evasión fiscal y otros delitos.

\section{Referencias}

Alonso, José Luis (2014) “Menéndez, rey de la Patagonia” Ed. Catalonia, Santiago.

Basualdo, Eduardo et al (2017) "Endeudar y fugar" ,Siglo XXI, CABA.

Beinstein, Jorge (2017) "Macri. Origen e instalación de una Dictadura mafiosa" PIA,Branzen

Beinstein, Jorge(2019) “Narco-mafias y capitalismo global”(en prensa)

Cerruti, Gabriela (2010)“E1 Pibe” Planeta, CABA.

Cerruti, Gabriela (2018) "Big Macri” Planeta,CABA

Cibeyra, Fernando(2017) "Macristocracia”, Planeta, CABA.

Cieza, Daniel (2016) “La presencia del poder económico en el Gobierno de Macri” en Revista de Trabajo y Derechos Humanos Nro 1,FCS-UBA,CABA

Delgado Jordán, Guillermo (2017) “Las redes del clan Braun” Sitio Nuestras Voces

Federico, Mauro (2011)"País narco" Sudamericana,CABA

Forgione, Francesco (2017) "La 'ndrangheta” El Viejo Topo, Barcelona.

Forgione, Francesco (2010) "Mafias en torno al deporte más popular del mundo" en Carrion,Fernando y

Rodríguez, Maria "Luchas urbanas alrededor del futbol" Flacso,Ecuador

Galasso, Norberto (2015 "Mauricio Macri. La vuelta al pasado" Colihue, CABA

Lieutier, Ariel(2010) “Esclavos”'Retórica,CABA

Lindner, Franco(2017) “La cabeza de Macri”Planeta,CABA

Maradeo, Julián- Damiani,Ignacio(2018) “Radiografía de la corrupción PRO”Planeta,CABA 
Reconfiguracion del capital en la Argentina. El debate sobre la fraccion hegemonica en el gobierno de Macri* CIEZA, D.

Mandel, Ernest(1971) Ensayos sobre el neocapitalismo. México, ERA

Premici, Sebastián(2016) "De patrones y peones" Acercándonos, CABA

Rafele, Esteban et al(2017) "El otro yo. Nicolás Caputo" Planeta,CABA

Tokatlian, Juan (2017) "Que hacer con las drogas" Siglo XXI, Buenos Aires

Torres, José Luis(2017) “Los Macri: De Reggio de Calabria a la Casa Rosada” en Revista Trabajo y Derechos Humanos, FCS_UBA,CABA.

Torres, José Luis(2016) “Los Braun-Menendez” en Revista Trabajo y Derechos Humanos Nro 2 FCS_ UBA, CABA

Vommaro,Gabriel et al(2015) “Mundo Pro" Planeta,CABA 